\title{
Electro-osmotic fluxes in multi-well electro-remediation processes
}

\author{
RUBÉN LÓPEZ-VIZCAÍNO, CRISTINA SÁEZ, ESPERANZA MENA, JOSE \\ VILLASEÑOR, PABLO CAÑIZARES AND MANUELA. RODRIGO**
}

Department of Chemical Engineering, University of Castilla-La Mancha, Ciudad Real, Spain.

\section{ABSTRACT}

In recent years, electrokinetic techniques on a laboratory scale have been studied but few applications have been assessed at full-scale. In this work, a mock-up plant with two rows of three electrodes positioned in semipermeable electrolyte wells has been used to study the electro-osmotic flux distribution.

Water accumulated in the cathodic wells when an electric voltage gradient was applied between the two electrode-well rows. Likewise, slight differences in the water flux were observed depending on the position and number of electrodes used and on the voltage gradient applied. Results show that the electro-osmotic flow did not increase proportionally with the number of electrodes used. During the start-up of the study, there was an abrupt change in the current density, $\mathrm{pH}$ and conductivity of the soil portions closest to electrodic wells due to electrokinetic processes. These differences can be explained in terms of the complex current distributions from anode and cathode rows. 
Keywords: electro-osmosis, electrochemical technology, soil remediation, electrolytic well, mock-up.

*Manuel Andrés Rodrigo, Department of Chemical Engineering, Facultad de Ciencias Químicas, Universidad de Castilla-La Mancha, Campus Universitario s/n, 13071 Ciudad Real, Spain, Phone: +34 902204100 ext. 3411; Fax: +34 926295256; E-mail:

Manuel.Rodrigo@uclm.es 


\section{INTRODUCTION}

Industrial and agricultural activities may cause pollution problems in soils and groundwaters. This type of pollution has a complex impact and, when evaluating this type of contamination, one must take into account the amount of soil, the physicochemical properties of the pollutants, the geological and chemical characteristics of the soil, the vegetable cover, the climatology of the zone, the affected area, etc. Among other consequences, the pollution of underground or superficial water reservoirs must be highlighted as a serious issue since this water will subsequently be unavailable for domestic supplies.

In the last few years, a great variety of technologies have been developed to address the problem discussed above ${ }^{[1-6]}$. Among these approaches, it is important to underline the electrokinetic techniques, which are the result of different processes (electromigration, electrophoresis, electro-osmosis, electrolysis and electrical heating) that occur in a soil when a DC electric potential is applied through a group of electrodes sited in the soil ${ }^{\text {[6- }}$ 17]. This technology is especially recommended for the treatment of low-permeability soils polluted with ionic pollutants, although it can also be used to remove non-ionic organic pollutants (in conjunction with surfactant solutions).

In electrokinetic processes the soil acts as an electrochemical cell. Soils themselves are not electrically or ionically conductive materials as the moisture is the real electrolyte in these electrochemical processes. For this reason, electrokinetic processes often require the addition of flushing fluids to guarantee hydraulic saturation, enhance the conductivity of soils, and to maintain the ionic circuit in the soil. In addition, the 
flushing fluid may contain substances that favour the treatment by increasing the mobility of the pollutants.

A number of manuscripts have focused on this topic in recent years ${ }^{[18-32]}$. Most of these studies were carried out on the laboratory scale and the soil electro-remediation reactors consisted of a hermetic column or a rectangular cell with a volume of less than $1 \mathrm{dm}^{3}$. In such cases, extrapolation of the results to a real application without an actual scale-up would almost certainly be unreliable. Moreover, due to the complex nature of a real soil, a model system is generally used in such studies. In this context, Kaolin is frequently used as a model for low-permeability soils ${ }^{[24,29,33-41]}$.

One of the novel aspects of the work described here is the scale of the study. Experimental work was carried out in a mock-up plant with a volume of $175 \mathrm{dm}^{-3}$ and it was intended to simulate a real electrokinetic treatment of contaminated soil. The electrodes were positioned in semipermeable electrolyte wells with a linear distribution (two rows of three electrodes in a face-to-face arrangement). Both the electrolyte wells and the soil were at atmospheric pressure as the electrokinetic reactor was an open system. The aim of the work was to increase our knowledge of the fluid flow distribution in a multi-well electrokinetic system and to determine the influence on this process of different parameters such as current density and operation time. 


\section{MATERIALS AND METHODS}

\section{Materials}

Kaolinite was selected as a model for clay soil. This soil is characterized by its inertness, low hydraulic conductivity, lack of organic content and low cation exchange capacity. The properties of the particular synthetic soil used in this study are given in Table 1. In each case, water was used as a flushing fluid. The water contained different salts in order to simulate superficial water. The properties of the flushing-water are given in Table 2.

\section{Experimental setup}

All of the electrokinetic experiments were carried out in a mock-up electro-remediation plant. The soil was loaded into an electrochemical reactor $(\mathrm{LWH}=70 \times 50 \times 50 \mathrm{~cm}$ ) that was constructed from a methacrylate polymer. The model soil consisted of two materials: kaolin and gravel, which was used to simulate the unsaturated stratum (17 $\mathrm{dm}^{3}$ ). The electrode distribution was two rows of three electrodes separated by $40 \mathrm{~cm}$ and positioned face to face. The electrodes with same polarity were separated by $12 \mathrm{~cm}$; these electrodes were located in semipermeable electrolyte wells. Porous graphite was selected as the material for the anodes and cathodes and these had a height of $10 \mathrm{~cm}$. A constant voltage gradient (ranging from 0.5 to $2.0 \mathrm{VDC} \mathrm{cm}^{-1}$ ) was applied using a power supply (Delta Elektronika BV, with a maximum output of $400 \mathrm{~V}$ and $4 \mathrm{~A}$ ). Under these experimental conditions, the current intensity ranged from 0.2 to $0.5 \mathrm{~A}$. 
The flushing fluid was injected into the anodic wells through electro-valves. These valves were controlled by a level controller sited within the wells. The cathodic wells were connected to three sewers of $0.1 \mathrm{dm}^{3}$ each. The objective of these sewers was to collect all of the fluid transported through soil. Before starting the experiments, the cathodic and anodic wells were filled with supply-water. The setup of the mock-up electro-remediation plant is shown in Figure 1.

\section{Experimental procedure}

Initially, the soil was moistened with water (with the composition shown in Table 2). The initial target moisture level for the kaolin was 30-34\% approximately. At this moisture level the soil is completely saturated with water. All of the electrokinetic experiments were operated under a constant voltage gradient (ranging from 0.5 to 2 VDC/cm). In each experiment the system was allowed to reach a steady state, which was assumed to be accomplished when the electric current was stable. The cell current, volume accumulated in cathodic sewers, electrolyte $\mathrm{pH}$ and conductivity at the anodic and cathodic compartments were measured periodically during the experiments. Conductivity and $\mathrm{pH}$ measurements at different positions of the soil allowed the variable profiles to be determined from the anode to cathode side.

\section{RESULTS AND DISCUSSION}

The time-course of the resulting electric current on applying a constant voltage gradient

of $0.5 \mathrm{VDC} \mathrm{cm}^{-1}$ between the two electrode-well rows of the mock-up is shown in Figure 2 (the row of three anodic wells and the row of three cathodic wells were 
arranged as shown in Figure 1). In all cases water (with the composition shown in Table 2) was used as the flushing fluid and this was continuously added to the anodic wells in order to maintain the electrolyte level in the well and, hence, moisture saturation within the synthetic soil.

It can be seen that the electric current was initially low (around $0.12 \mathrm{~A}$ ). The current then began to increase to a constant value of around $0.2 \mathrm{~A}$ after 4 hours of operation. After this point, the current intensity stayed at this value during the remaining operation time, thus confirming the steady state operation.

The increase in the current intensity during the start-up can be explained by the increase in the concentration of ions in the soil due to the electrolysis of water, which leads to the production of protons within the anodic wells and hydroxyl anions in the cathodic wells. The $\mathrm{pH}$ in the electrolyte wells is represented in Figure 3 along with the resulting $\mathrm{pH}$ profile of the soil between the anode and cathode rows at the initial time and after 2 , 4 and 6 hours of operation. As can be observed, during the initial stages of the study there was an abrupt change in the value of the electrolyte-well $\mathrm{pH}$ from the initial value (pH 8) to $\mathrm{pH} 2$ and $\mathrm{pH} 12$ in the anode and cathode wells, respectively. Similar results were reported by Chang and Liao ${ }^{[42]}$, Maini et al. ${ }^{[43]}$ and Lee and Yang ${ }^{[44]}$. Consequently, the $\mathrm{pH}$ in the soil portions closest to the electrodic wells underwent changes due to the movement of the acidic front towards the cathode and of the basic front towards the anode. In addition, the transport of ions through the soil by means of electro-osmotic flows - and especially by electromigration - produced the observed $\mathrm{pH}$ profile in the soil. The $\mathrm{pH}$ in the soil in the central zone of the electro-remediation reactor was maintained around the initial value due to neutralization of acidic and basic 
fronts. Taking into account that the acid front moves more rapidly than the basic front, the neutralization zone seems to be transported to the cathodic area ${ }^{[45,46]}$. Likewise, and as stated for the time-course of the current intensity, after an operation time of 4 hours the steady-state response was obtained for the $\mathrm{pH}$ profile and further changes were not observed with the operation time.

The trend observed in the conductivity can also be explained by considering the electrolysis and the resulting $\mathrm{pH}$ profile. The average conductivity profiles between the anode and cathode wells obtained at the initial time and after 2, 4 and 6 hours of testing are shown in Figure 4 (the same behaviour is observed in the three rows as for the $\mathrm{pH}$ ). It can be seen that the accumulation of ions $\left(\mathrm{H}^{+}, \mathrm{OH}^{-}\right)$inside the electrolytic wells leads to an increase in the conductivity of both electrolyte wells. However, the soil conductivity does not seem to change significantly and a flat profile (around $3 \mathrm{mS} \mathrm{cm}^{-1}$ ) is observed with time.

During this experiment, the accumulation of water was observed in the sewers located next to the cathodic wells (which were designed to collect the water that enters and flows out of the cathodic wells). The variations in the electro-osmotic flux, as calculated taking into account the volume of water collected in each well, during the $7 \mathrm{~h}$ of operation of the mock-up are represented in Figure 5. It is evident that the water flux obtained in the three wells fluctuates by around $0.16 \mathrm{dm}^{3} \mathrm{dm}^{-2} \mathrm{day}^{-1}\left( \pm 0.03 \mathrm{dm}^{3} \mathrm{dm}^{-}\right.$ ${ }^{2} \mathrm{day}^{-1}$ ). However, slight differences in the water flux are observed depending on the position of the well (left, central or right). It is feasible that these variations are related to possible heterogeneities in the soil or to irregularities in the packing of the soil, which could favour the appearance of preferential routes in a large-scale plant such as the one 
described in this work. However, it is more likely that these differences are related to complex current distributions from anode and cathode rows, as discussed below. Unfortunately, it is difficult to make a direct comparison with results published in literature because the water flux is greatly influenced by a number of factors such as soil properties and voltage gradient.

The variation of the electro-osmotic flow with the voltage gradient applied is shown in Figure 6. Voltage values ranged from 0.25 to $2.00 \mathrm{VDC} \mathrm{cm}^{-1}$. The global electroosmotic flow (which summarizes the contribution of the three wells) increases in an almost linear manner with the voltage gradient applied $\left(E_{z}\right)$. According to the theoretical model of Helmholz-Smoluchowski (Eq. 1), both parameters are related to the electroosmotic conductivity, where $\mathrm{J}_{\mathrm{eo}}$ is the electro-osmotic flux, $D$ is the dielectric constant, $\varepsilon_{\mathrm{o}}$ is the permittivity of a vacuum, $\zeta$ stands for zeta potential, $\eta$ denotes viscosity and $E_{z}$ is the electrical gradient.

$$
\mathrm{J}_{\mathrm{eo}}=-\frac{D \varepsilon_{0} \zeta}{\mu} E_{z}=K_{e} E_{z}
$$

A linear fitting of experimental results to eq. 1 provides a value for the electro-osmotic conductivity of data of $K_{\mathrm{e}}=1.06 \times 10^{-8} \mathrm{~m}^{2} \mathrm{~s}^{-1} \mathrm{~V}^{-1}$.

The electro-osmotic flow distribution in the collection wells on using different feeding wells or combinations is shown in Figure 7. All experiments were carried out at a constant potential of $40 \mathrm{~V}$ between rows of anodes and cathodes. It can be observed that the electro-osmotic flowrate and current intensity depend strongly on the number of 
anodes and cathodes. Likewise, it can be observed that the cathodic wells positioned face to face with the anodic wells accumulate higher volumes of water. Thus, for example, on using the central anodic well and two cathodic wells, the collector located next to the central cathodic well assumed $56.2 \%$ of the global electro-osmotic flux while $43.8 \%$ of the flux was accumulated in the side well.

On the other hand, the influence of the number of cathodes seems to be more significant than that of the number of anodes. However, the electro-osmotic flow is not proportional to the number of electrodes used. Thus, in the case of using the central anodic well the electro-osmotic flowrate increased by around $41 \%$ (from 0.586 to 0.829 $\mathrm{dm}^{3} \mathrm{dm}^{2} \mathrm{day}^{-1}$ ) when the number of cathodes was increased from 1 to 3 . Nevertheless, the increment obtained on increasing the number (while keeping the central anodic well constant) was only around $30 \%$ (from 0.586 to $0.76 \mathrm{dm}^{3} \mathrm{dm}^{2} \mathrm{day}^{-1}$ ). Likewise, as can be observed in Figure 7, there are no significant differences in the global electro-osmotic flux collected in the cathodic wells when the total number of electrodes was changed from 5 to 6 , regardless of the position of the disconnected well.

The global electro-osmotic flux accumulated in the row of cathodic wells as a function of the combination of wells is shown in Figure 8. It can be seen that the positions of both the anode and cathode wells used and the number of wells used influence the electrokinetic movement of the water through the soil. On using a single anodic or cathodic well sited in the central position of the row well, the electro-osmotic flow increased as the number of electrodes of opposite polarity increased. In contrast, in the case of using electrodes located in a side position of the row well, the trend for the electro-osmotic flux depended on the polarity of the fixed electrode. Thus, the electro- 
osmotic flowrate increased slightly with the number of cathodes when a single side anodic well is use. On the other hand, on using a single cathodic well in a side position, the flowrate decreased with the number of anodes connected.

The variations in the electro-osmotic flux in each well during the first 2 hours of operation in four of the different combinations studied are represented in Figure 9. In all cases the electro-osmotic flow remained constant with time. In addition, slight differences in the water flux were observed depending on the position of the well (left, central or right) and on the well combination used. According to the results shown in Figure 9, these differences may be related to complex current distributions from anode and cathode rows. Thus, in the case of using a central anodic well the water flux obtained in the three cathodic wells fluctuates around $0.27 \mathrm{dm}^{3} \mathrm{dm}^{-2} \mathrm{day}^{-1}( \pm 0.01$ $\left.\mathrm{dm}^{3} \mathrm{dm}^{-2} \mathrm{day}^{-1}\right)$. However, when a side anodic well is used the water flux strongly depends on the position of the cathodic well: $0.18,0.22$ and $0.29 \mathrm{dm}^{3} \mathrm{dm}^{-2} \mathrm{day}^{-1}$ in the left, central and right wells, respectively.

\section{CONCLUSIONS}

The main conclusions that can be drawn from this work are as follows:

- When an electric voltage gradient is applied between two electrode-well rows (one with cathodes and one with anodes) sited in a clay soil, accumulation of water in sewers placed next to the cathodic wells occurs. This electro-osmotic flux has a linear dependence on the voltage gradient.

- Transport of the ions produced during the electrolysis of water (inside electrodic wells) through the soil produces $\mathrm{pH}$ and conductivity profiles with both time and 
position, and an increment of the current intensity during the start-up of a electrokinetic process. A steady-state response was obtained for all of these three parameters after an operation time of 4 hours.

- The electro-osmotic flowrate depends strongly on the number of anodes and cathodes and on the position of these electrodes. The influence of the number of cathodes seems to be more significant than that of the number of anodes. These differences can be explained by the complex current distributions from anode and cathode rows.

\section{ACKNOWLEDGEMENTS}

This work was supported by the MCT (Ministerio de Ciencia y Tecnología, Spain) and by the EU (European Union) through projects CTM2007-60472/TECNO and CTM2010-18833/TECNO. 


\section{REFERENCES}

[1] Conte, P.; Agretto, A.; Spaccini, R.; Piccolo, A. Soil remediation: humic acids as natural surfactants in the washings of highly contaminated soils. Environ. Pollut. $\mathbf{2 0 0 5}, 135,515-522$.

[2] Gan, S.; Lau, E.V.; Ng, H.K. Remediation of soils contaminated with polycyclic aromatic hydrocarbons (PAHs). J. Hazard. Mater. 2009, 172, 532-549.

[3] Mulligan, C.N.; Yong, R.N.; Gibbs, B.F. Remediation technologies for metalcontaminated soils and groundwater: an evaluation. Eng. Geol. 2001a, 60, 193-207.

[4] Mulligan, C.N.; Yong, R.N.; Gibbs, B.F. Surfactant-enhanced remediation of contaminated soil: a review. Eng. Geol. 2001b, 60, 371-380.

[5] Pazos, M.; Alcántara, M.T.; Cameselle, C.; Sanromán, M.A. Evaluation of electrokinetic technique for industrial waste decontamination. Sep. Sci. Technol. 2009, 44, 2304-2321.

[6] Reddy, K.R. Technical Challenges to In-Situ Remediation of Polluted Sites. Geotech. Geol. Eng. 2010, 28, 211-221.

[7] Acar, Y.B.; Alshawabkeh, A.N.; Gale, R.J. Fundamental aspects of electrokinetic remediation of soils. Waste Manage. 1993a, 13, 5-8. 
[8] Acar, Y.B.; Gale, R.J.; Alshawabkeh, A.N.; Marks, R.E.; Puppala, S.: Bricka, M.; Parker, R. Electrokinetic remediation: Basics and technology status. J. Hazard. Mater. 1995, 40, 117-137.

[9] Alshawabkeh, A.N. Electrokinetic soil remediation: Challenges and opportunities. Sep. Sci. Technol. 2009, 44, 2171-2187.

[10] Garcia-Gutierrez, M.D.; Gomez-Lahoz, C.; Rodriguez-Maroto, J.M.; VeredaAlonso, C.; Garcia-Herruzo, F. Electrokinetic remediation of a soil contaminated by the pyritic sludge spill of Aznalcollar (SW, Spain). Electrochim. Acta. 2007, 52, $3372-3380$.

[11] Page, M.M.; Page, C.L. Electroremediation of contaminated soils. J. Environ. Eng. 2002, 128, 208-230.

[12] Pazos, M.; Ricart, M.T.; Sanromán, M.A.; Cameselle, C. Electrochim. Acta. Enhanced electrokinetic remediation of polluted kaolinite with an azo dye. 2007, 52, 3393-3398.

[13] Saichek, R.E.; Reddy, K.R. Enhanced Remediation of Hydrophobic Organic Compounds in Soils: A Review. Environ. Sci. Technol. 2005, 35, 115-189.

[14] Sarahney, H.; Wang, J.; Alshawabkeh, A.N. Electrokinetic Process for Removing $\mathrm{Cu}, \mathrm{Cr}$, and As from CCA-Treated Wood. Environ. Eng. Sci. 2005, 22, 642-650. 
[15] Shrestha, R.A.; Pham, T.D.; Sillanpää, M. Remediation of Chrysene from Contaminated Soil by Enhanced Electrokinetics. Int. J. Electrochem. Sci. 2009, 4, 1387-1394.

[16] Zhou, D.M.; Cang, L.; Alshawabkeh, A.N.; Wang, Y.J.; Hao, X.Z. Pilot-scale electrokinetic treatment of a $\mathrm{Cu}$ contaminated red soil. Chemosphere. 2006, 63, 964971.

[17] Virkutyte, J.; Sillanpää, M.; Latostenmaa, P. Electrokinetic soil remediation — critical overview. Sci. Total. Environ. 2002, 289, 97-122.

[18] Chang, J.H.; Qiang, Z.; Huang, C.P.; Ellis, A.V. Phenanthrene removal in unsaturated soils treated by electrokinetics with different surfactants-Triton X-100 and rhamnolipid. Colloids Surf. A. 2009, 348, 157-164.

[19] Couto, H.; Massarani, G.; Biscaia, E.; Sant'Anna, G.L. Remediation of sandy soils using surfactant solutions and foams. J. Hazard. Mater. 2009, 164, 1325-1335.

[20] Khalladi, R.; Benhabiles, O.; Bentahar, F.; Moulai-Mostefa, N. Surfactant remediation of diesel fuel polluted soil. J. Hazard. Mater. 2009, 164, 1179-1185.

[21] Laha, S.; Tansel, B.; Ussawarujikulchai, A. Surfactant-soil interactions during surfactant-amended remediation of contaminated soils by hydrophobic organic compounds: A review. J. Environ. Manage. 2009, 90, 95-100. 
[22] Maturi, K.; Reddy, K.R.; Cameselle, C. Surfactant-enhanced Electrokinetic Remediation of Mixed Contamination in Low Permeability Soils. Sep. Sci. Technol. 2009, 44, 2385-2410.

[23] Paria, S. Surfactant-enhanced remediation of organic contaminated soil and water. Adv. Colloid. Interface Sci. 2008, 138, 24-59.

[24] Park, J.Y.; Lee, H.H.; Kim, S.J.; Lee, Y.J.; Yang, J.W. Surfactant-enhanced electrokinetic removal of phenanthrene from kaolinite. J. Hazard. Mater. 2007, 140, 230-237.

[25] Pazos, M.; Rosales, E.; Alcántara, T.; Gómez, J.; Sanromán, M.A. Decontamination of soils containing PAHs by electroremediation: A review . J. Hazard. Mater. 2010, 177, 1-12.

[26] Pham, T.D.; Shrestha, R.A.; Sillanpää, M. Removal of Hexachlorobenzene and Phenanthrene from Clayey Soil by Surfactant and Ultrasound-Assisted Electrokinetics. J. Environ. Eng. 2010, 136, 739-743.

[27] Reddy, K.R.; Ala, P.R.; Sharma, S.; Kumar, S.N. Enhanced Electrokinetic Remediation of Contaminated Manufactured Gas Plant Soil. Eng. Geol. 2006, 85, 132-147. 
[28] Reddy, K.R.; Asce, M.; Saichek, R.E. Effect of Soil Type on the Electrokinetic Removal of Phenanthrene using Surfactants and Cosolvents. J. Environ. Eng. 2003, $129,336-347$.

[29] Reddy, K.R.; Maturi, K.; Cameselle, C. Sequential Electrokinetic Remediation of Mixed Contaminants in Low Permeability Soils. J. Environ. Eng. 2009, 135, 989999.

[30] Saichek, R.E.; Reddy, K.R. Effect of $\mathrm{pH}$ Control at the Anode for the Electrokinetic Removal of Phenanthrene from Kaolin Soil. Chemosphere. 2003, 51, 273-288.

[31] Wan, J.; Li, Z.; Lu, X.; Yuan, S. Remediation of a hexachlorobenzenecontaminated soil by surfactant-enhanced electrokinetics coupled with microscale Pd/Fe PRB. J. Hazard. Mater. 2010, 184, 184-191.

[32] Zhou, W.; Zhu, L. Enhanced soil flushing of phenanthrene by anionic-nonionic mixed surfactant. Water Res. 2008, 42, 101-109.

[33] Al-Hamdan, A.Z.; Reddy, K.R. Electrokinetic remediation modeling incorporating geochemical effects. J. Geotech. Geoenviron. Eng. 2008, 134, 91-106.

[34] Alcántara, M.T.; Gómez, J.; Pazos, M.; Sanromán, M.A. Electrokinetic remediation of PAH mixtures from kaolin. J. Hazard. Mater. 2010, 179, 1156-1161. 
[35] Alcántara, T.; Pazos, M.; Gouveia, S.; Cameselle, C.; Sanromán, M.A. Remediation of phenanthrene from contaminated kaolinite by electroremediationFenton technology. J. Environ. Sci. Health. Part A Toxic/Hazard. Subst. Environ. Eng. 2008a, 43, 901-907.

[36] Alcántara, T.; Pazos, M.; Cameselle, C.; Sanromán, M.A. Electrochemical remediation of phenanthrene from contaminated kaolinite. Environ. Geochem. Health. 2008b, 30, 89-95.

[37] Lee, Y.J.; Han, H.; Kim, S.H.; Yang, J.W. Combination of electrokinetic separation and electrochemical oxidation for acid dye removal from soil. Sep. Sci. Technol. 2009, 44, 2455-2470.

[38] Maturi, K.; Reddy, K.R. Cosolvent-enhanced desorption and transport of heavy metals and organic contaminants in soils during electrokinetic remediation. Water Air Soil Pollut. 2008, 189, 199-212.

[39] Oonnittan, A.; Shrestha, R.A.; Sillanpää, M. Removal of hexachlorobenzene from soil by electrokinetically enhanced chemical oxidation. J. Hazard. Mater. 2009, 162, 989-994.

[40] Pazos, M.; Cameselle, C.; Sanromán, M.A. Remediation of dye-polluted kaolinite by combination of electrokinetic remediation and electrochemical treatment. Environ. Eng. Sci. 2008, 25, 419-428. 
[41] Wang, J.Y.; Huang, X.J.; Kao, J.C.M.; Stabnikova, O. Simultaneous removal of organic contaminants and heavy metals from kaolin using an upward electrokinetic soil remediation process. J. Hazard. Mater. 2007, 144, 292-300.

[42] Chang, J.H.; Liao, Y.C. The effect of critical operational parameters on the circulation-enhanced electrokinetics. J. Hazard. Mater. 2006, 129, 186-194.

[43] Maini, G.; Sharman, A.K.; Knowles, C.J.; Sunderland, G.; Jackman, S.A. Electrokinetic remediation of metals and organics from historically contaminated soil. J. Chem. Technol. Biotechnol. 2000, 75, 657-665.

[44] Lee, H.H.; Yang, J.W. A new method to control electrolytes $\mathrm{pH}$ by circulation system in electrokinetic soil remediation. J. Hazard. Mater. 2000, 77, 227-241.

[45] Acar, Y.B.; Alshawabkeh, A.N.; Gale, R.J. Fundamentals of extracting species from soils by electrokinetics. Waste Manage. 1993b, 13, 141-152.

[46] Pamukcu, S. Electro-chemical technologies for in-situ restoration of contaminated subsurface soils. Electron. J. Geotech. Eng. 2007, 2. 


\section{Figure captions}

Figure. 1. Diagram (a) and photograph (b) of the mock-up electro-remediation plant.

Figure. 2. Variation of electric current and voltage gradient with time in the electroremediation process. Operation condition: $\mathrm{E}_{\mathrm{z}}=0.5 \mathrm{VDC} / \mathrm{cm}$.

Figure. 3. Variation of $\mathrm{pH}$ profile with time for electro-remediation process. a) $0 \mathrm{~h}$, b) 2 h, c) 4 h, d) 6h. Operation condition: $E_{z}=0.5 \mathrm{VDC} / \mathrm{cm}$, flushing solution = Water.

Figure. 4. Variation of conductivity with time for the electro-remediation process a) 0 h, b) $2 \mathrm{~h}, \mathrm{c}) 4 \mathrm{~h}, \mathrm{~d}) 6 \mathrm{~h}$. Operation condition: $\mathrm{E}_{\mathrm{z}}=0.5 \mathrm{VDC} / \mathrm{cm}$.

Figure. 5. Variation of electro-osmotic flux with time depending on electrolytic well. Operation condition: $\mathrm{E}_{\mathrm{z}}=0.5 \mathrm{VDC} / \mathrm{cm} . \diamond$ Left electrolytic well, $\bigcirc$ Central electrolytic well, $\Delta$ Right electrolytic well.

Figure. 6. Influence of voltage gradient in global electro-osmotic flux for the electroremediation process.

Figure. 7. Electro-osmotic flow distribution in the collection wells when different feeding wells or combinations are used. Operation condition: Cell potential $=40 \mathrm{~V}$. 
Figure. 8. Global electoosmotic flow as function of number of well used. a) $\diamond$ Central anode, $\square$ Side anode; b) $\diamond$ Central cathode, $\square$ Side cathode. Operation condition: Cell potential $=40 \mathrm{~V}$.

Figure. 9. Variation of electro-osmotic flow with time. $\diamond$ Right well, $\square$ Central well, $\triangle$ Left well. Operation condition: Cell potential $=40 \mathrm{~V}$. 
(a)

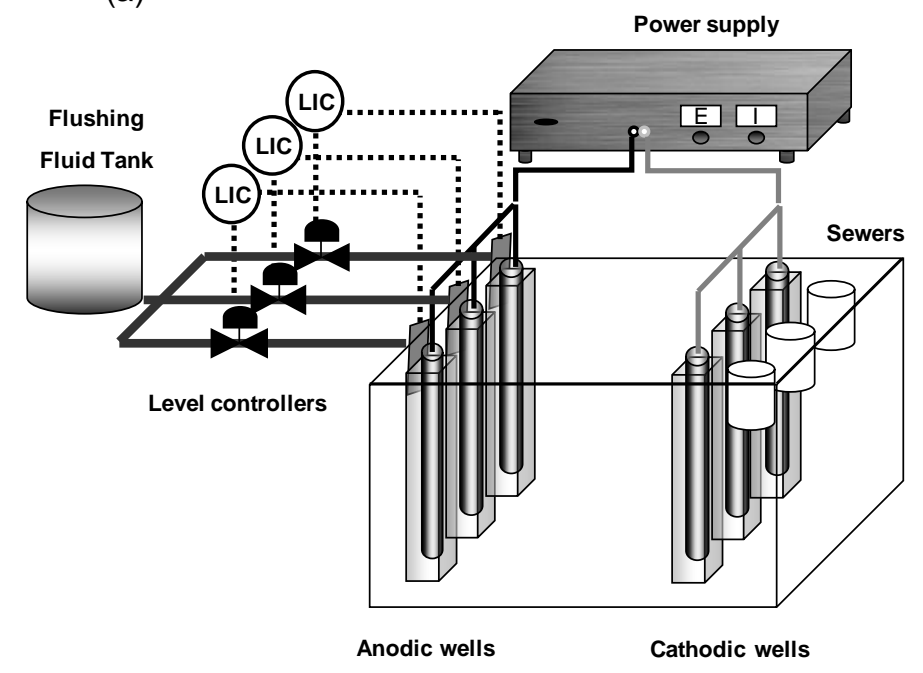

Figure 1 (b)

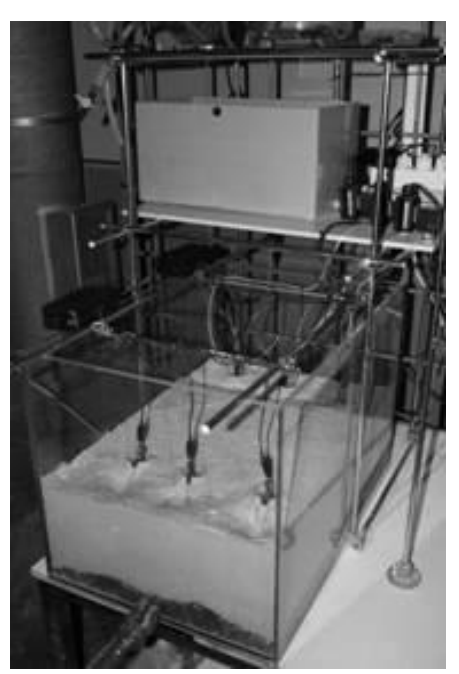




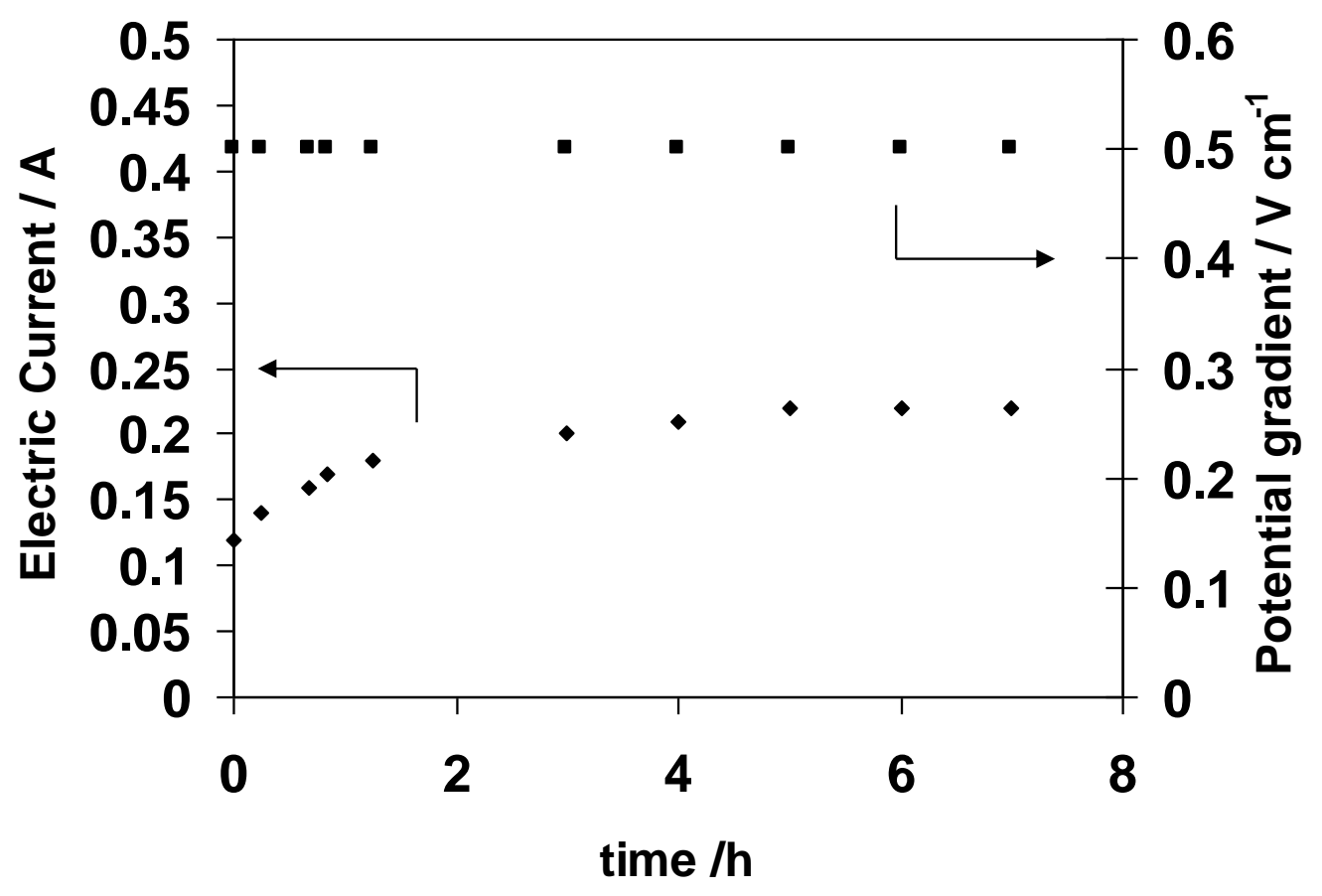

Figure 2. 

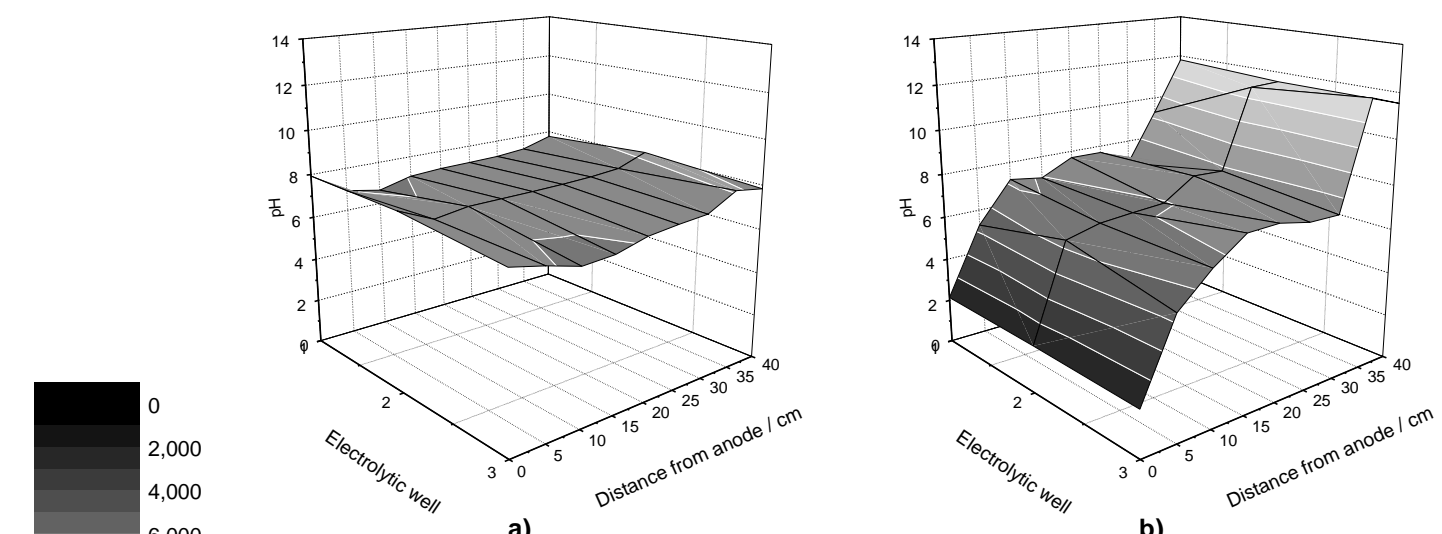

6,000

a)

b)

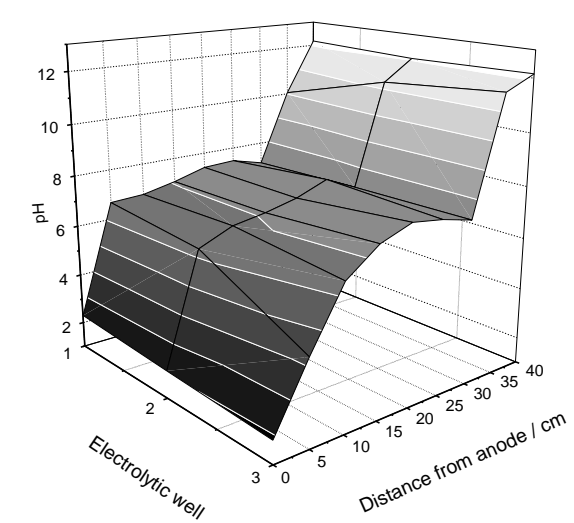

c)

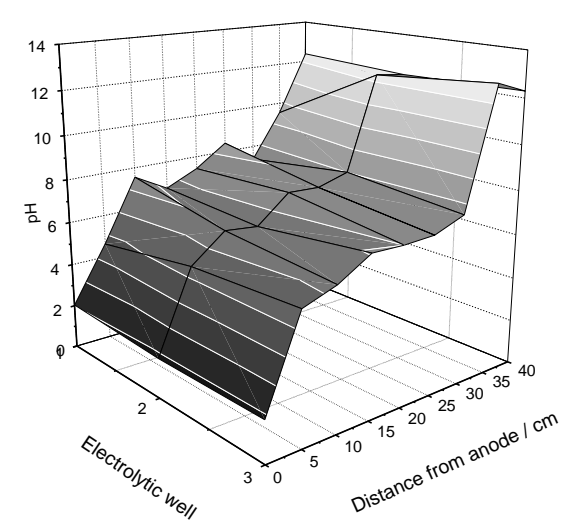

d)

Figure 3. 

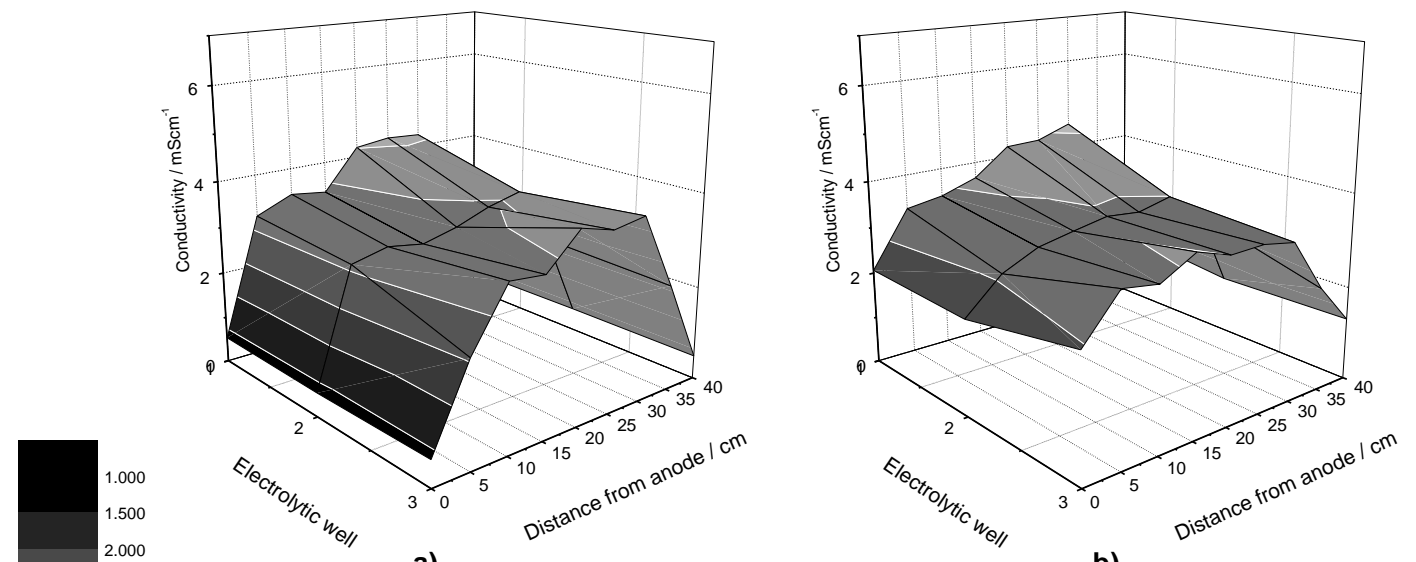

a)

b)

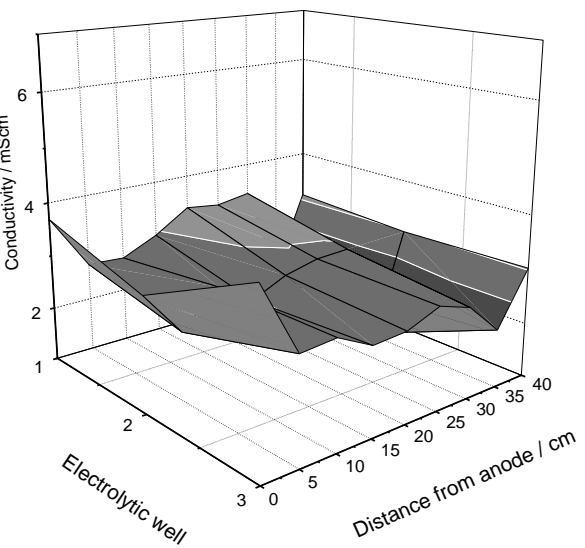

c)

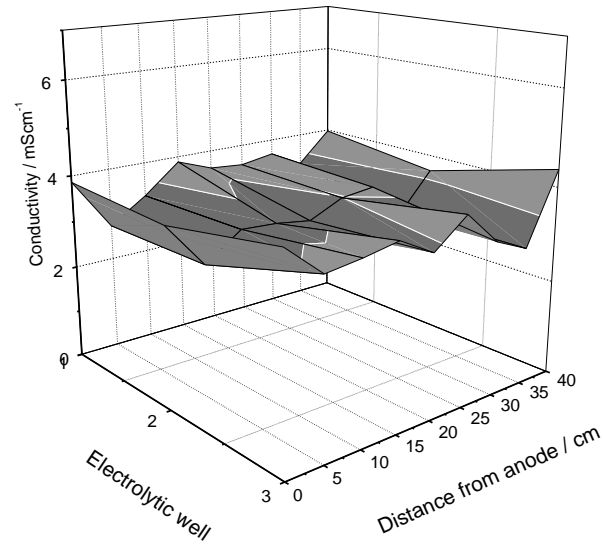

d)

Figure 4 


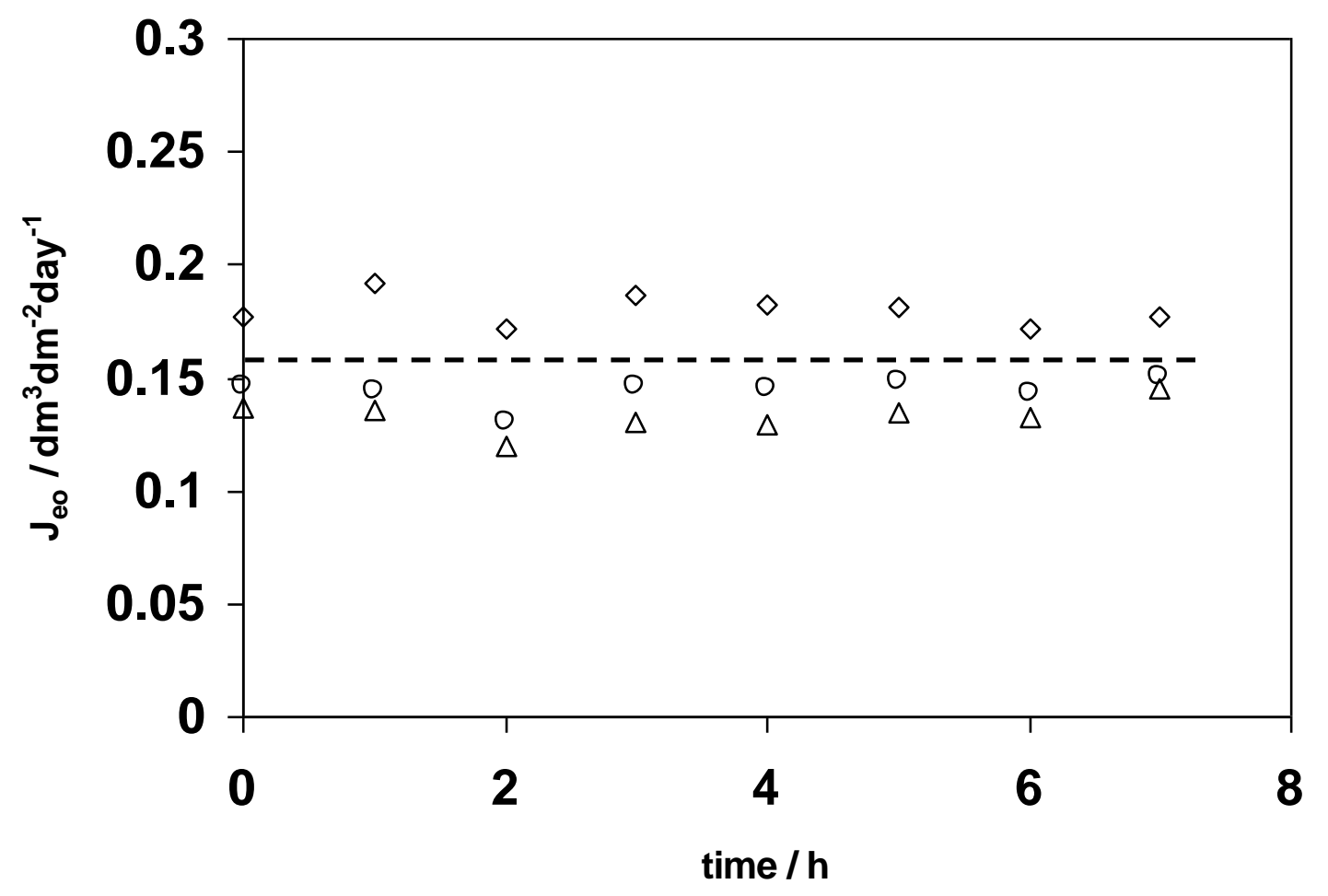

Figure 5. 


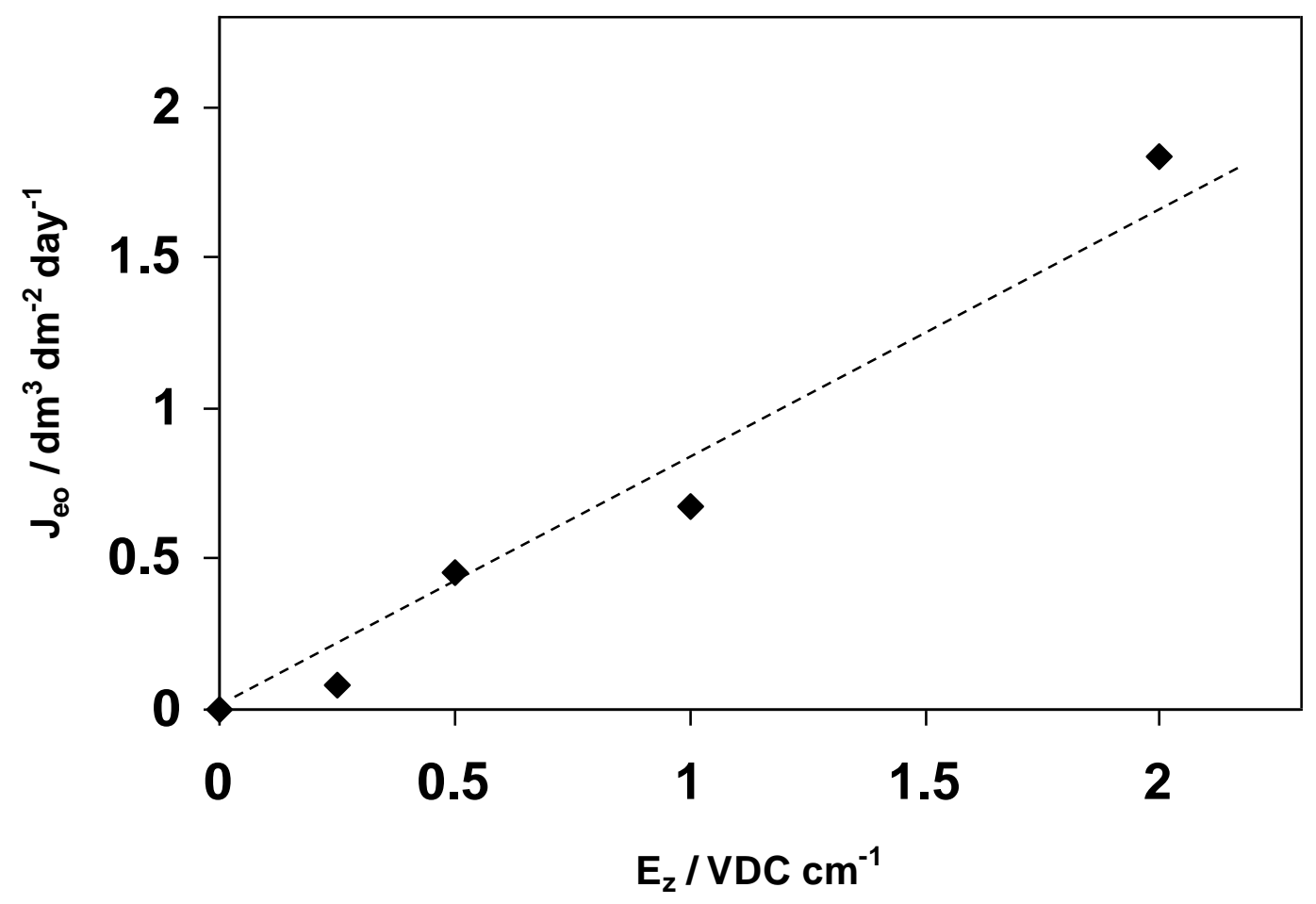

Figure 6. 


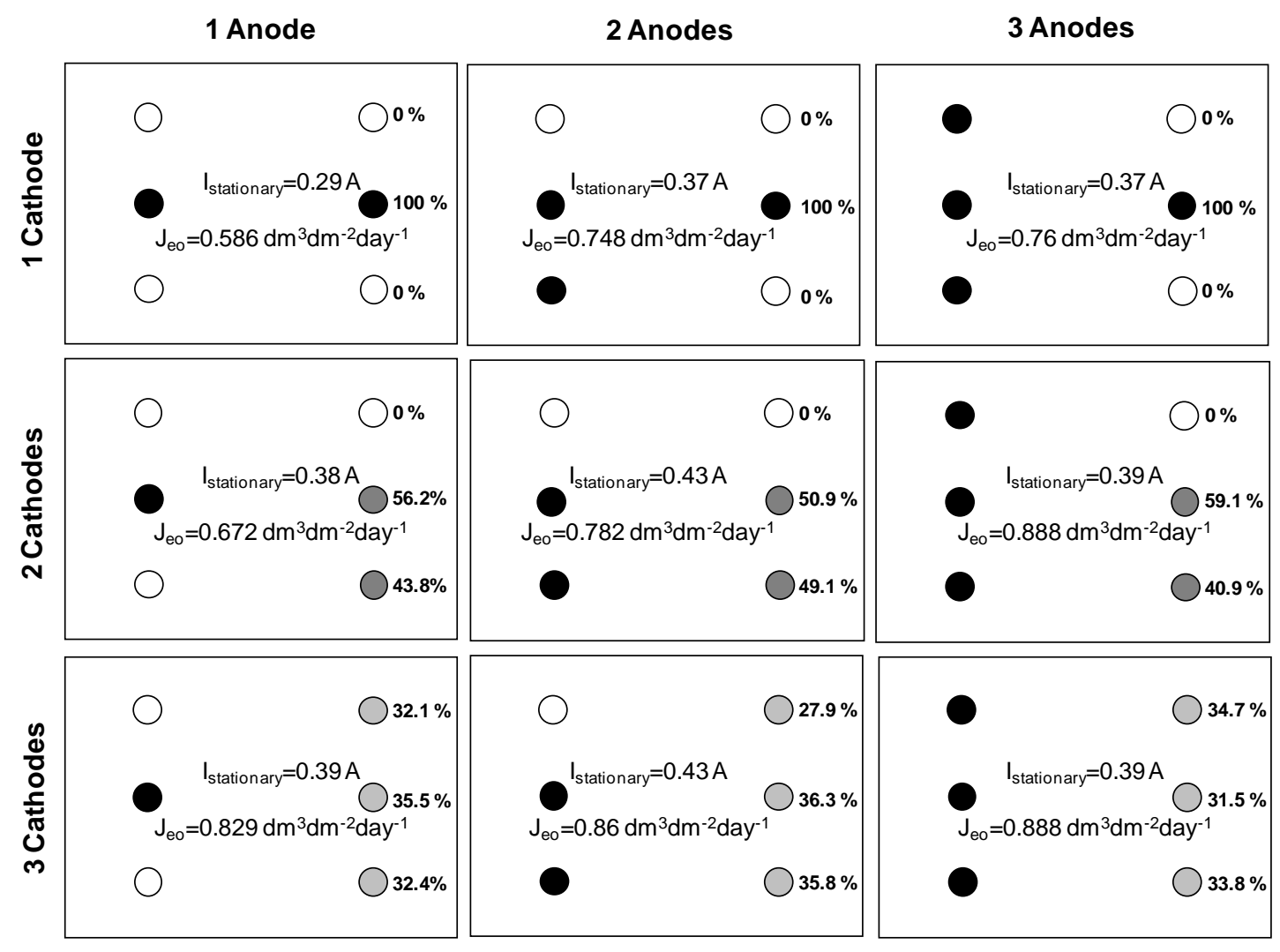

Figure 7 

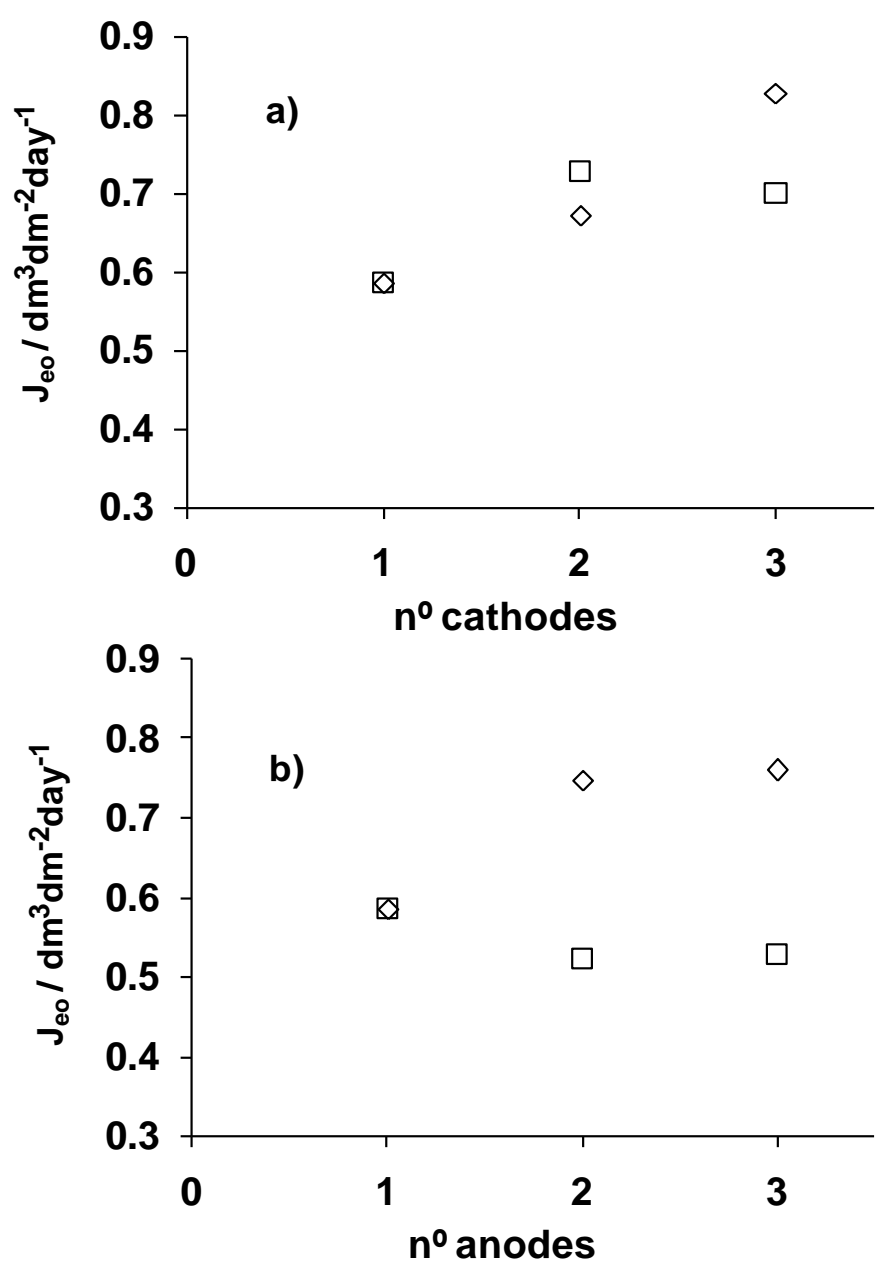

Figure 8. 

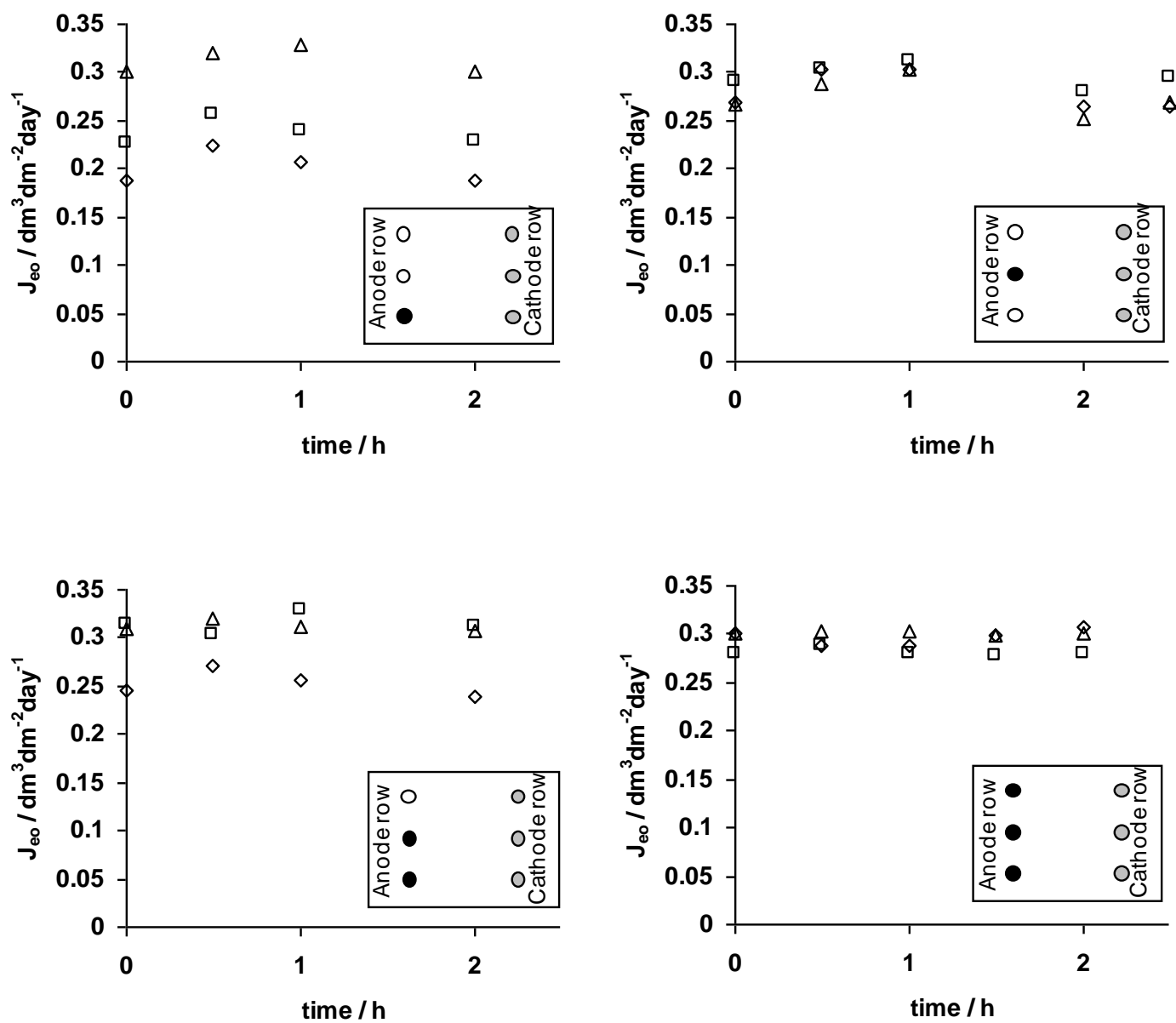

Figure 9. 
Table 1. Properties of soil.

\begin{tabular}{lr|lr}
\hline & & \multicolumn{2}{c}{ Particle size distribution (\%) } \\
\hline Kaolinite & $100.00 \%$ & Gravel & 0 \\
$\mathrm{Fe}_{2} \mathrm{O}_{3}$ & $0.58 \%$ & Sand & 4 \\
$\mathrm{TiO}_{2}$ & $0.27 \%$ & Silt & 18 \\
$\mathrm{CaO}$ & $0.10 \%$ & Clay & 78 \\
${ } }$ & $0.75 \%$ & Specific gravity & 2.6 \\
$\mathrm{SiO}_{2}$ & $52.35 \%$ & Hydraulic conductivity $(\mathrm{cm} / \mathrm{s})$ & $1 \times 10^{-8}$ \\
$\mathrm{Al}_{2} \mathrm{O}_{3}$ & $34.50 \%$ & Organic content $(\%)$ & 0 \\
Others & $11.42 \%$ & pH & 4.9 \\
\hline
\end{tabular}

Table 2. Water composition.

\begin{tabular}{|c|c|}
\hline \multicolumn{2}{|c|}{ Parameters } \\
\hline Conductivity / $\mathrm{mS} \mathrm{cm}^{-1}$ & 0.391 \\
\hline $\mathrm{pH}$ & 7.64 \\
\hline \multicolumn{2}{|c|}{ Salts concentration / $\mathrm{mg} \mathrm{dm}^{-3}$} \\
\hline $\mathrm{Ca}$ & 35.23 \\
\hline $\mathrm{Cl}^{-}$ & 57.26 \\
\hline $\mathrm{Fe}$ & 0.15 \\
\hline $\mathrm{F}$ & 0.702 \\
\hline $\mathrm{Mg}$ & 0.011 \\
\hline $\mathrm{Mn}$ & 0.048 \\
\hline $\mathrm{Na}$ & 12.09 \\
\hline K & 11.72 \\
\hline $\mathrm{NO}_{3}^{-}$ & 6.22 \\
\hline $\mathrm{SO}_{4}{ }^{2-}$ & 44.41 \\
\hline
\end{tabular}

